\title{
Torque Analysis of Faulty SRM using FEA-TFR Approach
}

\author{
Ilhem Bouchareb \\ LGEC lab of EE Dept., \\ University of Constantine 1, \\ Algeria
}

\author{
Amar Bentounsi \\ LGEC lab of EE Dept., \\ University of Constantine 1, \\ Algeria
}

\author{
Abdesselam Lebaroud \\ LGEC and Dept. of EE, \\ University of Skikda, \\ Algeria
}

\begin{abstract}
This paper presents an analysis of effects of dynamic air-gap eccentricity on the performances of a 6/4 Switched Reluctance Machine (SRM) through finite element analysis (FEA) based on a FEMM package associated to MATLAB/SIMULINK package software. Among the various Time-Frequency methods used for detection of defects, the Time-Frequency Representation (TFR) is an appropriate tool to detect the mechanical failures through the torque analysis by allowing a better representation independent from the type of fault. Simulation results of healthy and faulty cases are discussed and illustrate the effectiveness of the proposed approach.
\end{abstract}

\section{Keywords}

Eccentricity, FEA, SRM, Time-Frequency Representation, Wigner-Ville Distribution.

\section{INTRODUCTION}

In a wide variety of industrial applications, an increasing demand exists to improve the reliability and availability of electrical systems. Popular examples include systems in aircraft, electric railway traction, power plant cooling or industrial production lines. A sudden failure of a system in these examples may lead to cost expensive downtime, damage to surrounding equipment or even danger to humans. Monitoring and failure detection improves the reliability and availability of an existing system. Since various failures degrade relatively slowly, there is potential for fault detection at an early stage. This avoids the sudden, total system failure that can have serious consequences.

Electric machines are a key element in many electrical systems. Amongst all types of electric motors, switched reluctance drive is more fault tolerant than other drives, mostly because it can continue operating and produce torque with one or more of its phases not functioning. This is due in large part to the decoupling of the machine phases. This machine, however, is not fault free, and questions emerge as to diagnostic and detection methods.

Many authors have examined the effect of rotor eccentricity on the machine parameters and performance and developed different ways to model and to monitor the induction machines with air-gap eccentricity [1]-[20].

In the case of switched reluctance machine (SRM), the knowledge of the physical effects of eccentricities is not yet very complete. Among the researches, which studied SRM under dynamic eccentricity (DE) fault, we find in [21] a 6/4 SRM with dynamic eccentricity modeled and simulated using a coupled structural and electromagnetic 2D Finite Element Method (FEM).

A 3D FEM approach is applied in [22] for describing the performance characteristics of a 6/4 SRM under dynamic rotor eccentricity. This approach is also employed to evaluate the performance of the motor (including flux density, flux linkages, terminal inductance and mutual inductance profile) under different rotor positions and under different varying degree of angular misalignment fault in [23]. In [24] the same approach is used and a new hybrid method of obtaining the degrees of freedom for radial air-gap length in SRM operation under normal and faulty conditions based on magnetostatic analysis is presented. [25] proposes a mathematical model for calculating forces in novel switched reluctance bearingless motor (SRBM) with a single layer winding in eccentricity conditions.

A literature survey showed a lack of detection methods that account for the SRM mechanical fault effect. The most authors simply give the behavior of SRM under eccentricity without application of the methods of diagnosis that allows obtaining accurate results. Relatively few works study the influence of eccentricity on the dynamic response of SRM (output torque signal). Various Time-Frequency methods as Wigner-Ville Distribution (WVD), Spectrogram (SP) and Short-Time Fourier Transform (STFT) are used for fault detection.

In this article, the signal processing method, namely, TimeFrequency Representation (TFR), will be used to study the effect of dynamic air-gap eccentricity on the torque profile of an SRM as summarized in Fig 1.

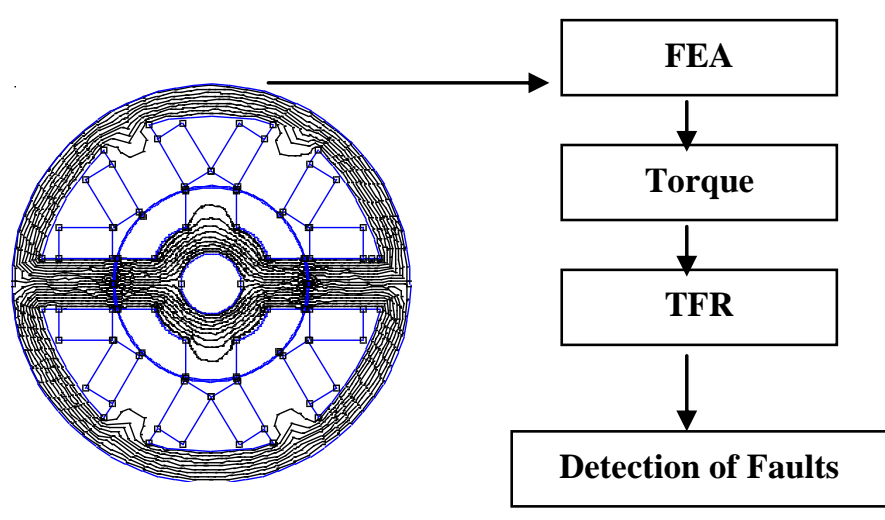

Fig 1: Algorithm for detection of dynamic eccentricity 
The paper is organized as follows: Section 2 describes the magnetostatic characteristics of a 6/4 SRM under dynamic eccentricity using 2D-FE model. Dynamic analysis using MATLAB/SIMULINK package is presented in section 3 . Section 4 gives the results of Time-Frequency analysis of the torque.

\section{MAGNETOSTATIC ANALYSIS USING FEMM}

Dynamic eccentricity (DE) is introduced as shown in Fig. 2. A dynamic eccentricity occurs when the center of the rotor is not at the center of rotation and the minimum air-gap revolves with the rotor. The risk of high levels of dynamic eccentricity is a mechanical contact between the rotor and the stator resulting in considerable damage for the machine. To investigate the effect of dynamic eccentricity on the $6 / 4$ switched reluctance behaviour, the motor is simulated utilizing 2-D finite element analysis by Finite Element Method Magnetics (FEMM) package [26]. Using finite elements method is a priori appealing for solving complex problems with a better accuracy.

A model of the switched reluctance machine cross section was created by using the FEMM package. Iron material was used in the structure of the stator and rotor cores with the following B-H curve shown in Fig 3. Number of turns in each phase equal to 120 and the winding of phase was excited with a current magnitude of $2 \mathrm{~A}$. The distribution of the magnetic flux density of the proposed SR machine in healthy situation and with different varying degrees of dynamic eccentricity is shown in the APPENDIX. Fig 4 and Fig. 5 reveal the magnetic flux distribution and density shadow in the case of the healthy machine and in the case of $40 \%$ dynamic eccentricity, respectively. From the comparing of the healthy and faulty cases, we observe that the flux density has increased with increasing the relative dynamic eccentricity. It is noted that CRR, $\mathrm{CgR}$ and $\mathrm{CgS}$ are the rotor rotation center, rotor symmetry center and stator symmetry center, respectively.

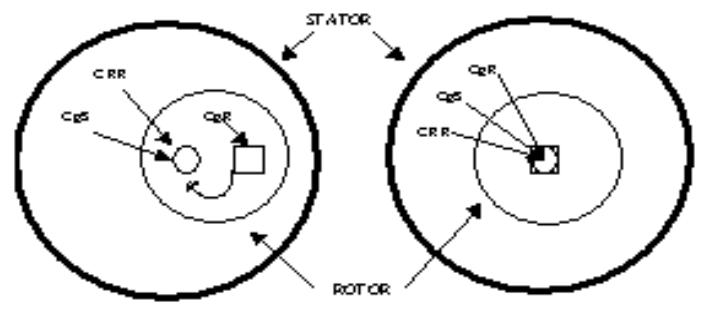

Fig 2: Schematic representation of DE

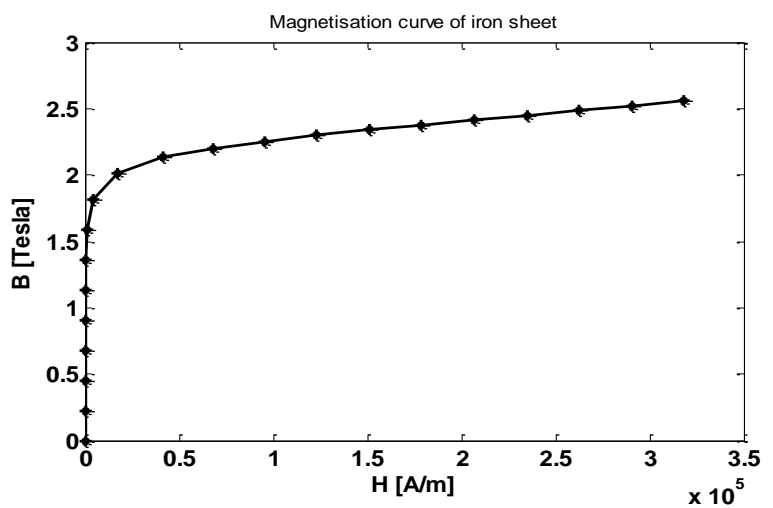

Fig 3: Magnetization curve of iron sheet
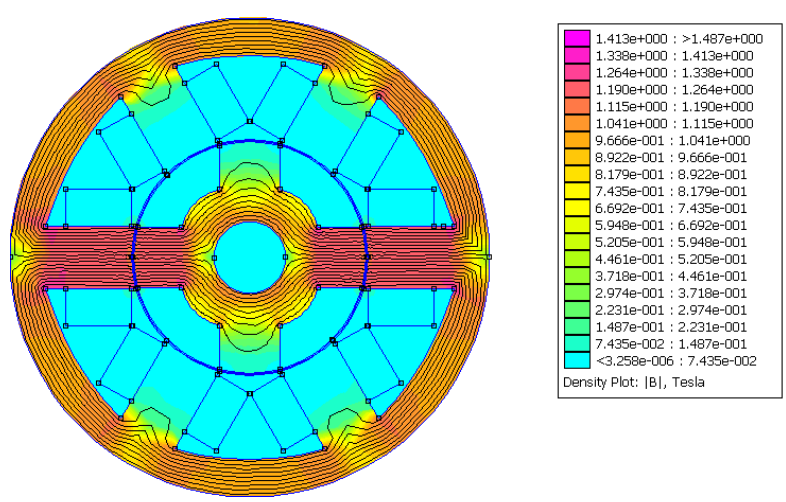

Fig 4: Flux distribution and density shadow due to excitation of phase $a$ in case of none eccentric air-gap
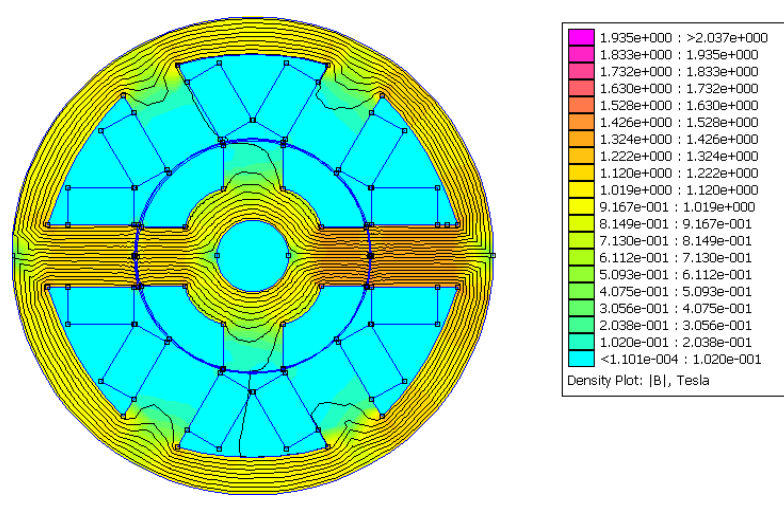

Fig 5: Flux distribution and density shadow due to excitation of phase $a$ in case of $40 \%$ eccentric rotor.

The data of the studied 6/4 SRM are shown in Table1. The static torque and the magnetizing flux linkages are obtained at different rotor positions from 0 to $90^{\circ}$ taking rotational steps of $5^{\circ}$ where the rotor moves from unaligned to fully aligned position. Static magnetic characteristics of the healthy motor and the motor with dynamic eccentricity fault are shown in Fig 6 and Fig 7, respectively.

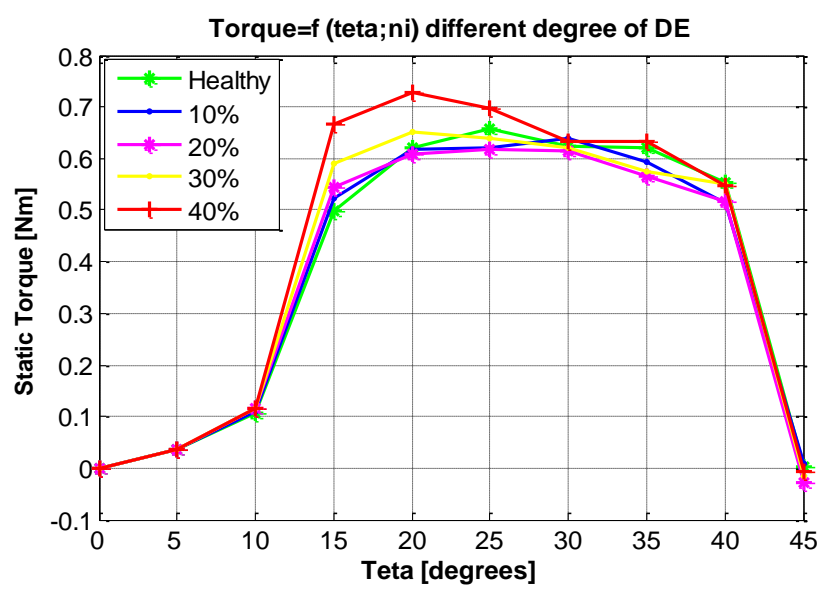

Fig 6: FE static torque of the SRM vs. rotor position: healthy and faulty cases with various \% of DE 


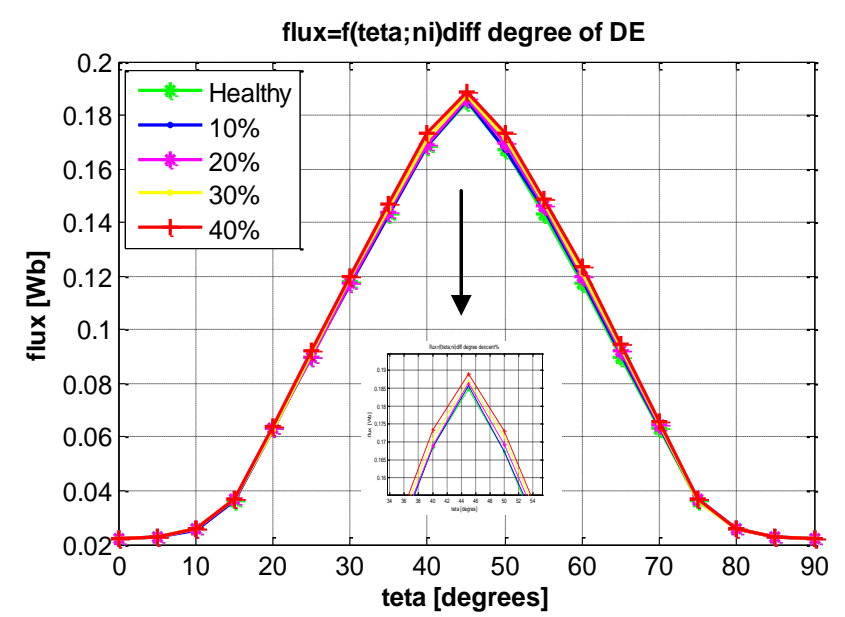

Fig 7: Flux distribution of the SRM vs. rotor position: healthy and faulty cases with various \% of DE

\section{DYNAMIC ANALYSIS USING}

\section{MATLAB}

In a previous paragraph, the studied 6/4 SRM was modeled by a finite element method (FEM) providing us the different magnetic data for the realization of the look-up tables. These data were provided in the matrix shape and made it possible to carry out the look-up tables for ten rotor positions, $\theta$, from $0^{\circ}$ to $+45^{\circ}$, and also ten different current values from 0 to $25 \mathrm{~A}$.

\subsection{Dynamic Equations of The SRM}

The mathematical model for predicting dynamic response of SRM under dynamic eccentricity is described by the following set of equations. The electric equation of each phase, $i=\{1,2,3\}$, is given by

$$
V_{i}=R i_{i}+\frac{d \psi_{i}\left(\theta, i_{i}\right)}{d t}
$$

The linkage flux in each phase is given by

$$
\Psi_{i}\left(\theta, i_{i}\right)=L(\theta) i_{i}
$$

The total energy associated with the three phases is

$$
\mathrm{W}_{\text {total }}=\frac{1}{2} \sum_{\mathrm{i}=1}^{3} \mathrm{~L}\left(\theta+(\mathrm{n}-\mathrm{i}-1) \theta_{\mathrm{s}}\right) \mathrm{i}_{\mathrm{i}}^{2}
$$

The total electromagnetic torque is

$$
\mathrm{C}_{\mathrm{e}}=\frac{1}{2} \sum_{\mathrm{i}=1}^{3} \frac{\mathrm{L}\left(\theta+(\mathrm{n}-\mathrm{i}-1) \theta_{\mathrm{s}}\right)}{\mathrm{d} \theta} \mathrm{i}_{\mathrm{i}}^{2}
$$

The mechanical equations are

$$
\begin{aligned}
& \mathbf{J} \frac{\mathrm{d} \omega}{\mathrm{dt}}=\mathrm{C}_{\mathrm{e}}-\mathrm{C}_{\mathrm{r}}-\mathrm{F} \omega \\
& \frac{\mathrm{d} \theta}{\mathrm{dt}}=\omega
\end{aligned}
$$

Where $\mathrm{Cr}$ represents the torque load, $\mathrm{F}$ is the viscous friction coefficient and $\omega$ is the angular speed.

This mathematical model enables computation of instantaneous values of phase currents, total torque and speed. The instantaneous total electromagnetic torque is obtained by summing instantaneous phase torque at instantaneous angular position. This value cannot be expressed analytically in terms of phase current, since magnetic saturation is present at loading of the SRM.

\subsection{Effect of Dynamic Eccentricity on Torque}

The following calculations derive the expression of the torque in presence of dynamic eccentricity. The reference [27] gives the relation between torque and air-gap length, $g$, as follows

$$
C e=\left[\frac{1}{8} k \mu_{0}\right]\left[\frac{N_{p h}^{2} D L}{g}\right] i^{2}
$$

The air-gap length $g(\theta)$ in case of an eccentric rotor can be modeled as

$$
g(\theta)=R s-a \cos \theta-b \sin \theta-R r \sqrt{1-\frac{1}{R_{r}{ }^{2}}(a \sin \theta+b \cos \theta)^{2}}
$$

In SRM, the air-gap is in general relatively small compared to the rotor radius, $R r(0.5 \mathrm{~mm}<<<58 \mathrm{~mm})$. Therefore, the rotor displacement described by $a$ and $b$ is also small compared to $R r$, and $\mathrm{g}(\theta)$ is commonly approximated by

$$
g(\theta) \approx g_{0}-a \cos \theta-b \sin \theta
$$

where $\mathrm{g} 0=(\mathrm{Rs}-\mathrm{Rr})$ is the mean air-gap length without eccentricity. The parameters $\mathrm{a}$ and $\mathrm{b}$ take different expressions with respect to the type of eccentricity and $\delta \mathrm{d}$ denote the degree of dynamic eccentricity. Then

$$
\begin{aligned}
& a=g_{0} \delta d \cos \theta r \\
& b=g_{0} \delta d \sin \text { Or } \\
& g(\theta) \approx g_{0}-a \cos \theta-b \sin \theta
\end{aligned}
$$

Formula (7) of the torque can be rearranged by using equations (8) to (11) as follows

$$
C e(\theta)=\left(\frac{k \mu_{0} N p h^{2} D L i^{2}}{8}\right) \frac{1}{g_{0}-g_{0} \delta d \cos (\theta+\theta r)}
$$

\subsection{Look-Up Table Construction}

In computing procedure solving the equation of the mathematical model the look-up table of the torque $\operatorname{Ce}(\theta, \mathrm{i})$ and flux linkage $\Psi(\theta, i)$ need to be known. The corresponding static characteristics of the studied SRM are represented in Fig 8 and Fig 9, respectively.

To solve the equation (1) the information about the magnetic circuit of the machine must be transformed from the form $\Psi=\mathrm{f}(\theta, \mathrm{i})$ into the form $\mathrm{i}=\mathrm{f}(\Psi, \theta)$ as shown in Fig 10 . The transformation is carried out by using $2 \mathrm{D}$ bicubic spline 
interpolation [27]. The function $\mathrm{i}=\mathrm{f}(\Psi, \theta)$ is then stored into the special SIMULINK block called "2D look-up table" to be used in MATLAB/SIMULINK. Another "2D look-up table" which is needed for the calculation of the instantaneous values of torque contains the function $\mathrm{Ce}=\mathrm{f}(\theta, \mathrm{i})$, which is also calculated before simulations using the function $\Psi=\mathrm{f}(\theta, \mathrm{i})$ and the equation (2). The position measurement units are electrical radians. The unaligned position corresponds to 0 electric radians and the aligned position - to $\pi$ electric radians.

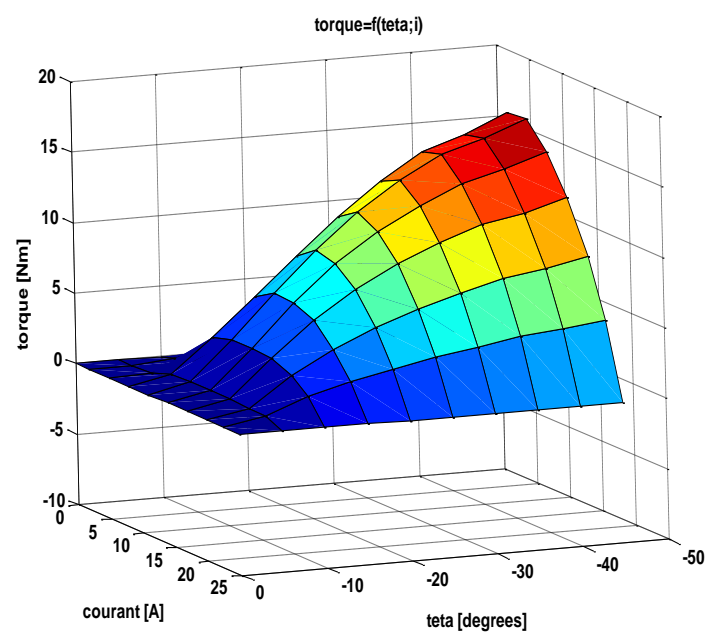

Fig 8: Plot of Torque vs. Current \& Rotor Position

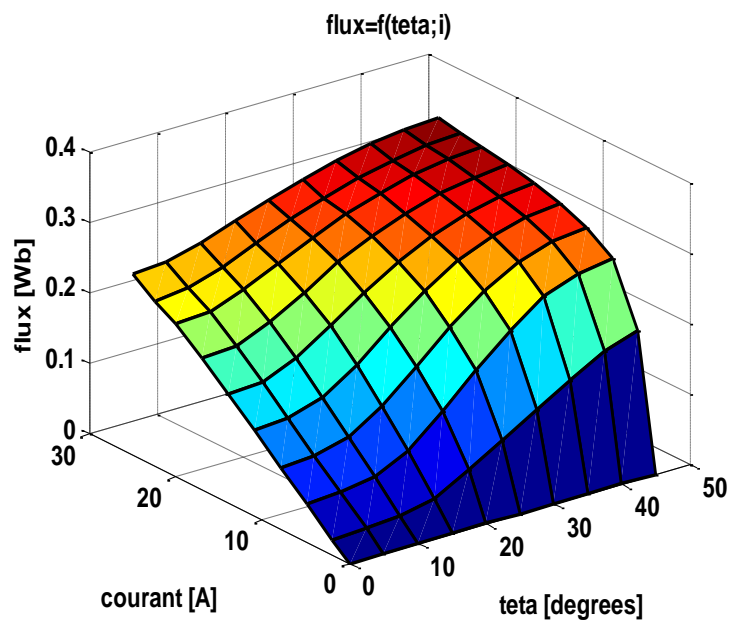

Fig 9: Plot of Flux vs. Current and Rotor Position

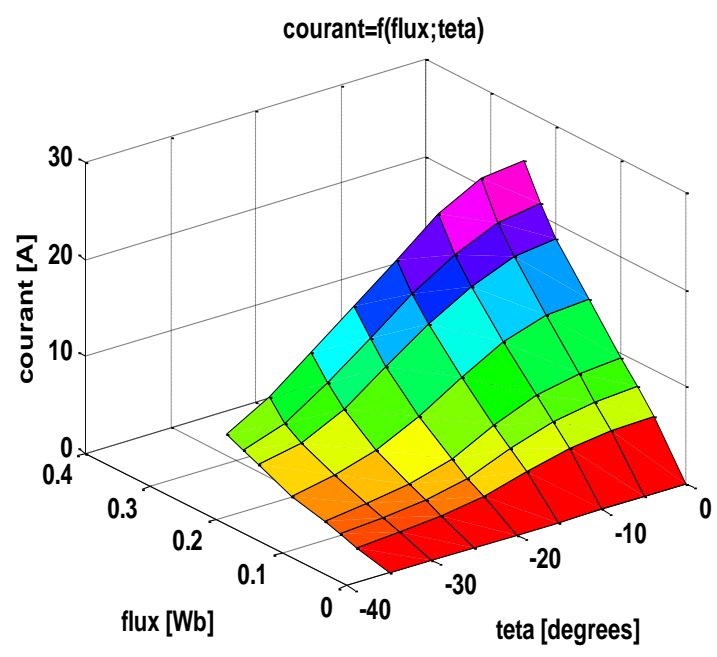

Fig 10: Plot of Current vs. Flux and Rotor Position

\subsection{Hysteresis Current Control}

Hysteresis current control represented in Figure 11 is the used energizing strategy for a SRM. Results of dynamic behavior of the SRM, shown in Figures 12, 13 and 14, have been achieved for $\theta \mathrm{on}=0^{\circ}, \theta \mathrm{off}=38^{\circ}$, and a current reference of Iref $=8 \mathrm{~A}$, with the motor functioning at no-load.

Two different cases, namely, a healthy case and an eccentric rotor case for conducting the analysis were created. In the first model, it is assumed that dynamic air- gap eccentricity is not present and, in the second model, dynamic air-gap eccentricity is introduced to see the effect of eccentric rotor on the torque behavior.

Manufacturers working to keep the total eccentricity level normally as low as possible in order to minimize unbalanced magnetic pull (UMP) and to reduce vibration and noise, for this an air-gap eccentricity up of $40 \%$ is not permissible due to collision of the rotor pole with stator pole. $40 \%$ dynamic air-gap eccentricity was assumed.

The healthy versus time plot is considered as reference values for the study of the faulted cases.

The torque versus time plotted in Figure 12 is given for the healthy machine, respectively for the faulty case. It is clear that the torque value and frequency have increased rapidly due to the dynamic air-gap eccentricity. The current through phases is regulated at the reference level by hysteresis control. Figure 13 shows the current waveforms of the healthy and faulty motor. It is observed that the frequency of current as well as the torque has doubled. Due to this fault the speed value increased from $135 \mathrm{rpm}$ to $300 \mathrm{rpm}$ as shown in Figure 14.

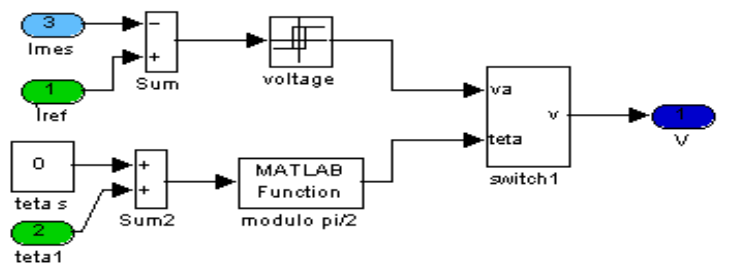

Fig 11: Detail on one phase's command bloc 

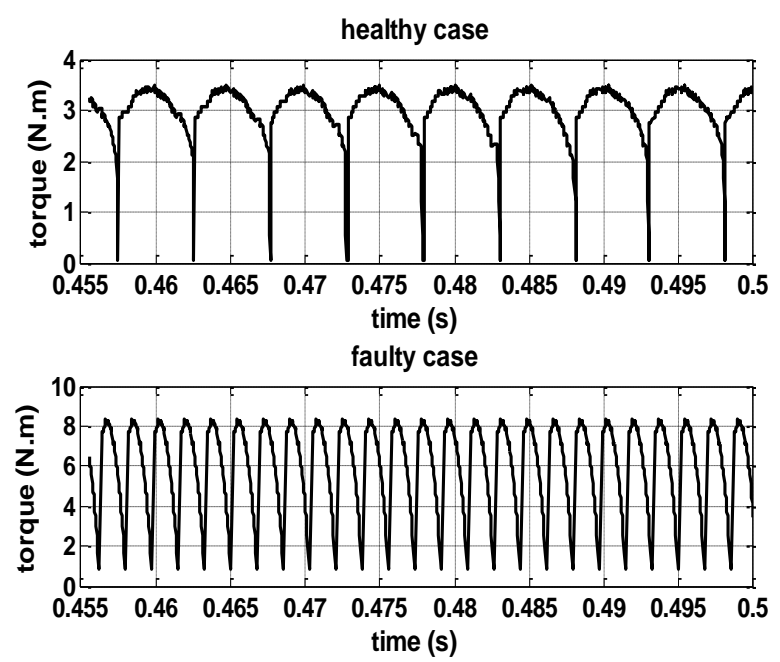

Fig 12: The Torque waveforms of the healthy and faulty motor under $40 \%$ of $\mathrm{DE}$

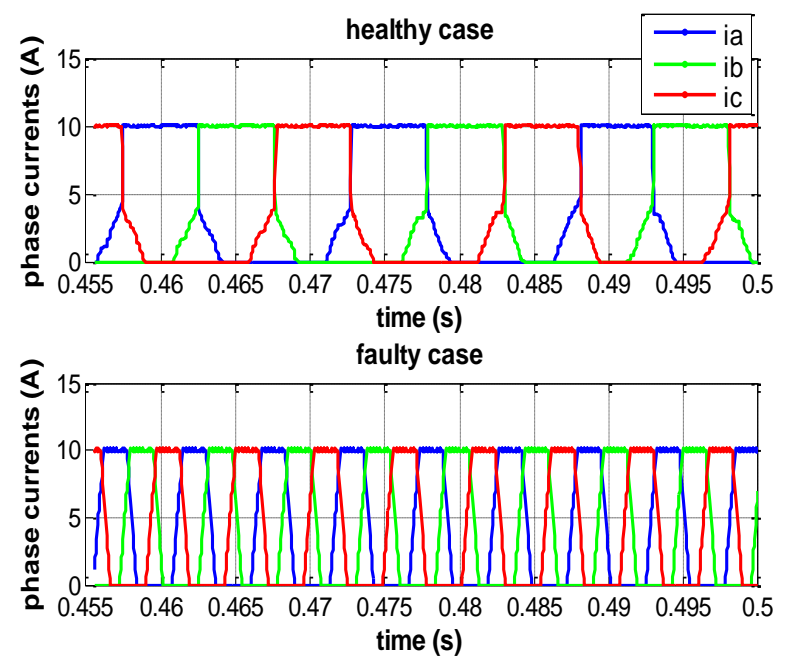

Fig 13: The Current waveforms of the healthy and faulty motor under $40 \%$ of $\mathrm{DE}$
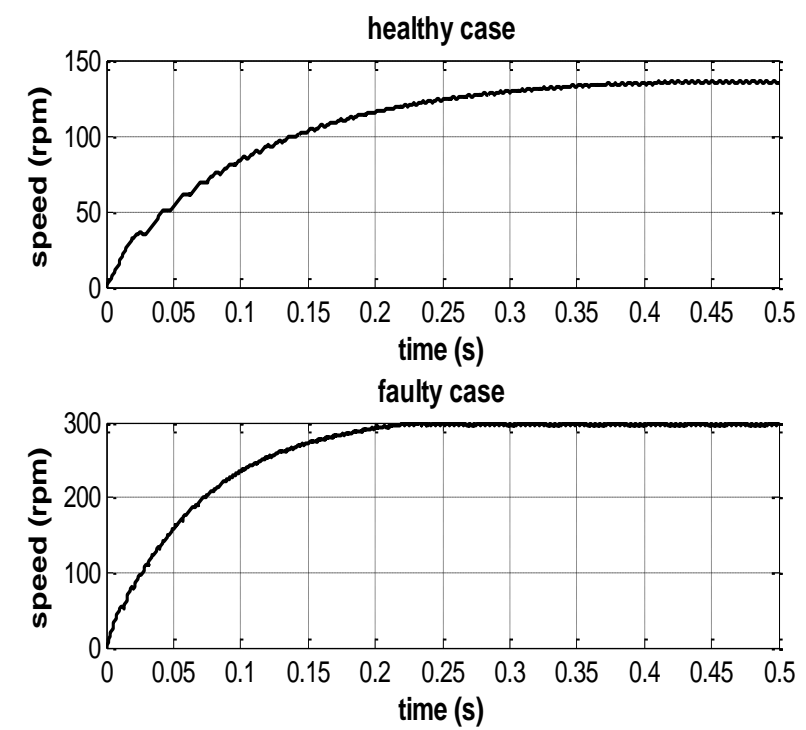

Fig 14: Speed waveforms of the healthy and faulty motor under $40 \%$ of $\mathrm{DE}$

\section{TIME-FREQUENCY ANALYSIS OF TORQUE}

In order to have a more informative description, various Time-Frequency Analysis (TFR's) as Wigner- Ville Distribution (WVD), Spectrogram (SP) and Short-Time Fourier Transform (STFT) have been taken to study the effect of dynamic air-gap eccentricity on the torque profile of an SRM in the healthy and faulty cases (an air-gap eccentricity of $40 \%$ was assumed).

The results obtained from Figure 15 to 20 shows that with dynamic eccentricity, the value of the torque is increased. The TFR method allows remarking the analysis in the characteristic failure; besides, it maximizes the failure relative value. Compared with SP and STFT, dynamic eccentricity of SRM torque (non-stationary signal) is clearly shown by WVD. The STFT assumes that the non-stationary signal is slowly changing in a chosen time window. This and the choice of window length impair the use of STFT at low frequencies or when the signal is changing very fast dynamically. This limits the use of STFTs.

The Wigner-Ville Distribution Wx $(t, f)$ of signal $x(t)$ is defined as

$$
W_{x(t, f)}=\int_{-\infty}^{+\infty} x\left(t+\frac{\tau}{2}\right) x^{*}\left(t-\frac{\tau}{2}\right) e^{-j 2 \pi f t} d \tau
$$

The Short-Time Fourier Transform of signal $x(t)$ is

$$
F_{x}^{w}(t, f)=\mathfrak{J} \rightarrow f\{x(\tau) w(\tau-t)\}=\int_{-\infty}^{+\infty} x(\tau) \cdot w(\tau-t) e^{-j 2 \pi f f d \tau}
$$

The squared Short-Time Fourier Transform is called the spectrogram and its expression is

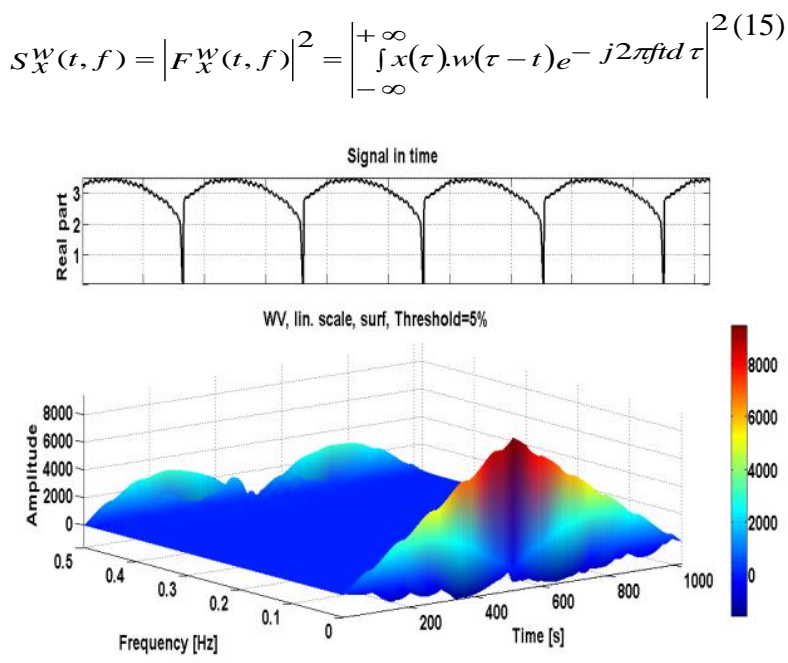

Fig 15: Wigner-Ville Distribution of the healthy torque 


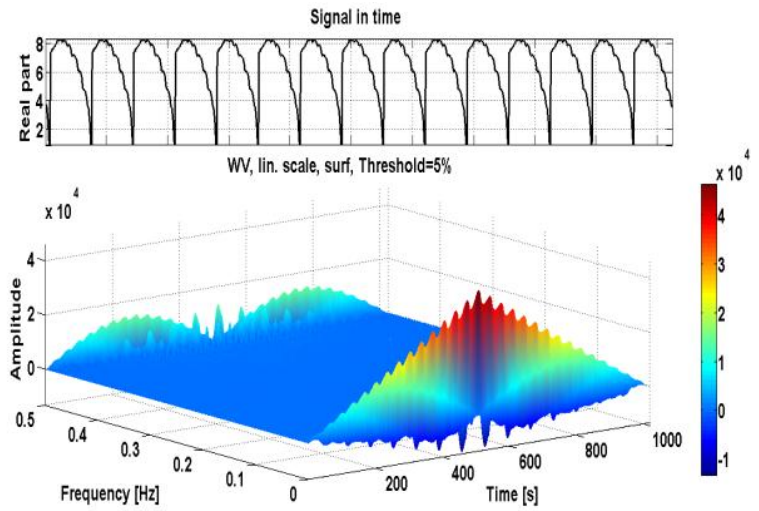

Fig 16: Wigner-Ville Distribution of the faulty torque
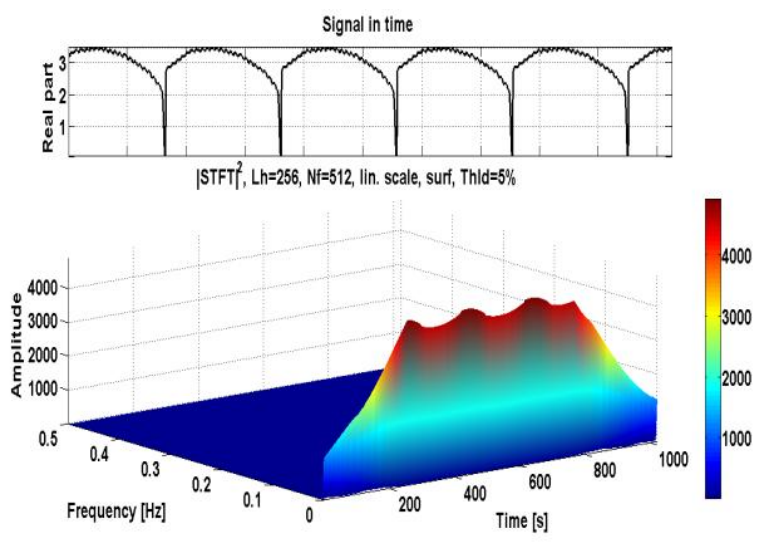

Fig 17: S-T Fourier Transform of the healthy torque
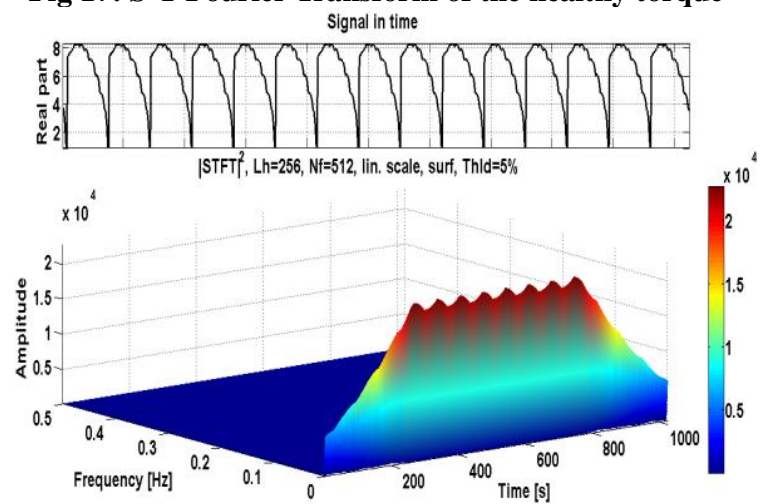

Fig 18: S-T Fourier Transform of the faulty torque
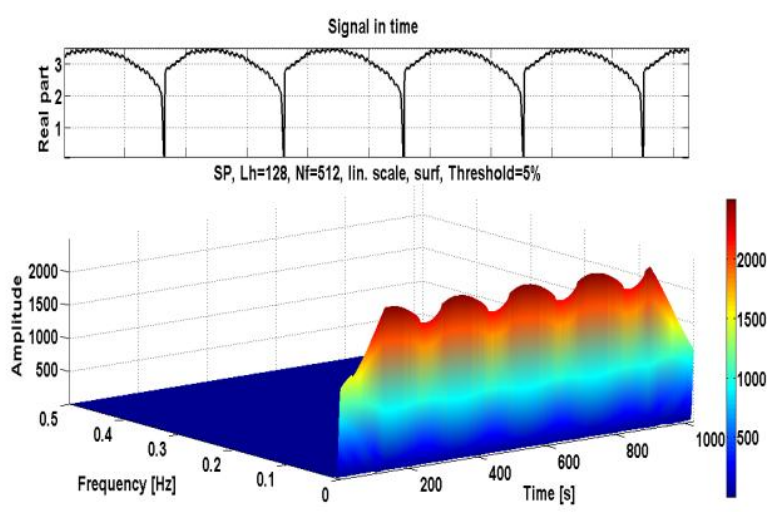

Fig 19: Spectrogram of the healthy torque
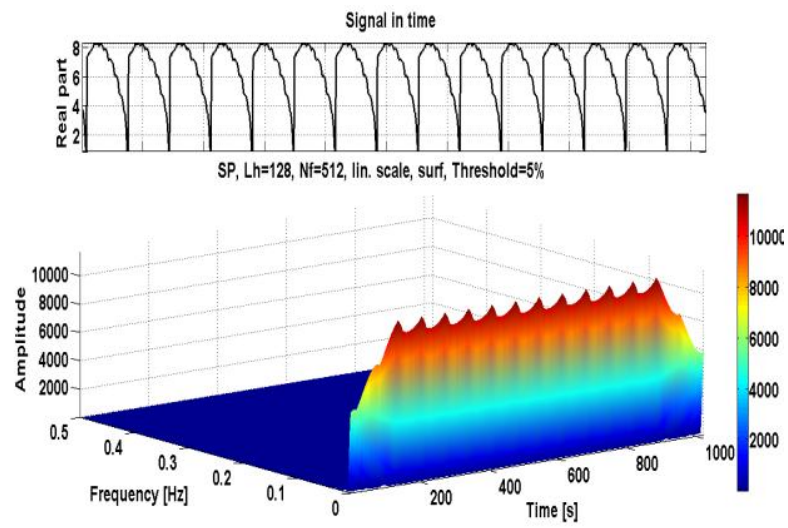

Figure 20: Spectrogram of the faulty torque

Table1. Parameters of the studied 6/4 SRM

\begin{tabular}{|c|c|}
\hline Quantity & Value \\
\hline Stator and rotor pole arc & $30^{\circ}$ \\
Stack length & $40 \mathrm{~mm}$ \\
Outer diameter & $120 \mathrm{~mm}$ \\
Rotor diameter & $58 \mathrm{~mm}$ \\
Shaft diameter & $18 \mathrm{~mm}$ \\
Air-gap length & $1 \mathrm{~mm}$ \\
Height of stator pole & $21.5 \mathrm{~mm}$ \\
Height of rotor pole & $11 \mathrm{~mm}$ \\
Stator or rotor yoke thickness & $9 \mathrm{~mm}$ \\
Number of turns per phase & 120 \\
\hline
\end{tabular}

In this paper, an important signal processing method, namely Time-Frequency Representation (TFR), is used for diagnosis of the dynamic eccentricity in SRM.

A detection model allows SRM behavior to be determined under different varying degree of dynamic eccentricity fault is built based on the Finite Element Method Magnetics (FEMM) combined with a MATLAB/SIMULINK simulation and lookup table of the torque and current. A mathematical model of the torque based on eccentricity has been developed.

It was proved that the value of the electromagnetic torque, speed and flux of the faulty motor is increased compared with that of the healthy motor. This could largely increase noise in the motor. Joint TFR in three-dimension show the ability of fault identify also reliability for the fault diagnosis and detection, the results were found to be in close agreement to the simulation results. 


\section{APPENDIX}

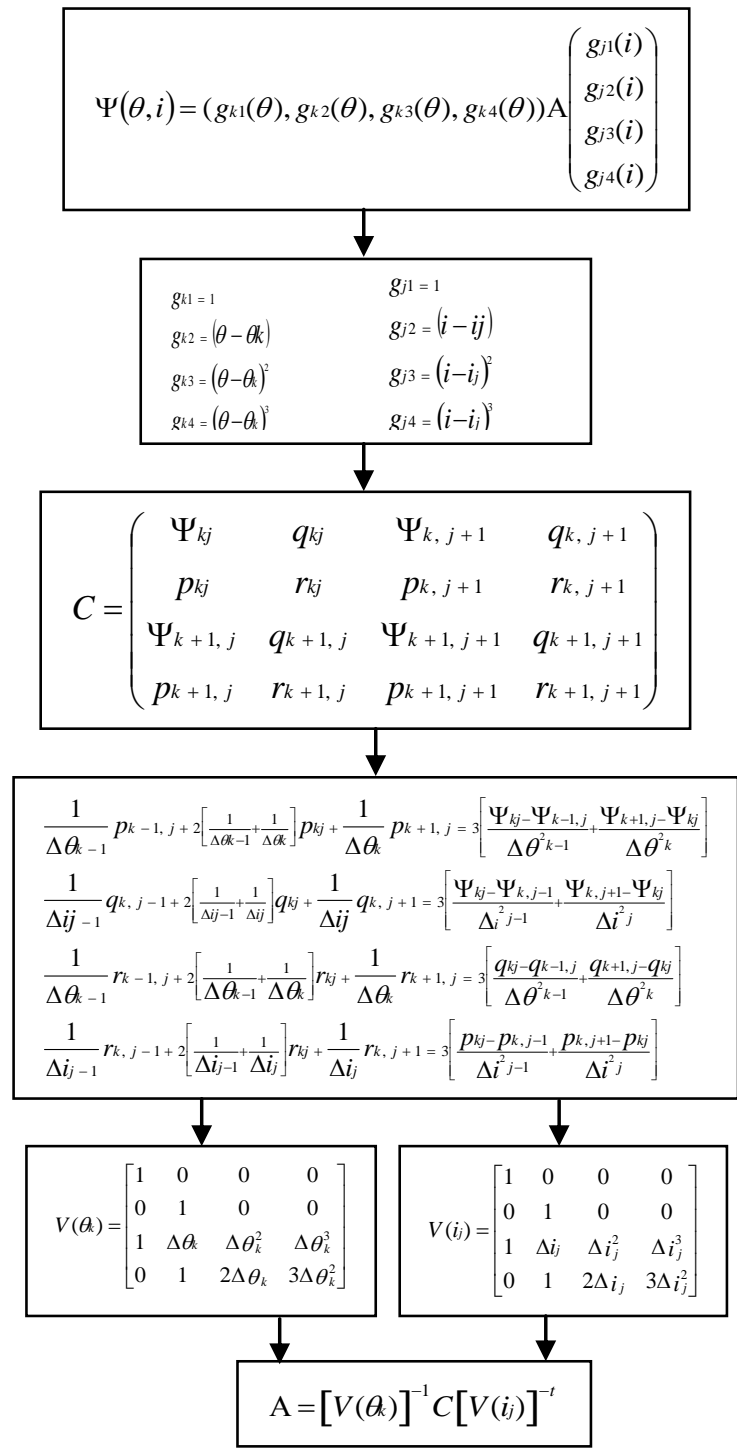

\section{REFERENCES}

[1] H. A. Toliyat, M. S. Arefeen, and A. G. Parlos, "A method for dynamic simulation of eccentricity in induction machines", IEEE-TIA, vol. 32, no. 4, pp. 910918, July/August 1996.

[2] Subhasis Nandi, Shehab Ahmed, and Hamid A. Toliyat, "Detection of Rotor Slot and Other Eccentricity Related Harmonics in a Three Phase Induction Motor with Different Rotor Cages", IEEE-Trans. on E.C., vol. 16, no. 3, pp. 253-260, September 2001.

[3] Subhasis Nandi, Raj Mohan Bharadwaj, and Hamid A. Toliyat, "Performance Analysis of a Three-Phase Induction Motor Under Mixed Eccentricity Condition", IEEE-Trans. on E.C., vol. 17, no. 3, September 2002.

[4] E. L. Bonaldi, L. E. Borges da Silva, G. Lambert-Torres, L. E. L. Oliveira and F. O. Assunção, "Using rough sets techniques as a fault diagnosis classifier for induction motors", IEEE 2002, $28^{\text {th }}$ Annual Conf. of IECON02, vol. 4, pp. 3383-3388, 5-8 Nov., 2002.
[5] M.L. Sin, W.L. Soong and N. Ertugrul," IM on-line condition monitoring and fault diagnosis-a survey", AUPEC, Christchurch, N.Z., 2003.

[6] J. Faiz, I. T. Ardekanei, and H. A. Toliyat, "An Evaluation of Inductances of a Squirrel-Cage Induction Motor Under Mixed Eccentric Conditions", IEEE Trans. on E.C., vol. 18, no. 2, pp. 252-258, June 2003.

[7] H. Hamidi, A.R. Nasiri and F. Taringoo, "Detection and Isolation of Mixed Eccentricity in Three Phase Induction Motor via Wavelet Packet Decomposition", 5th Asian Control Conf., ASCC2004, vol. 2, pp. 1371-1376, 20-23 July 2004.

[8] Sang-Hyuk Lee, Sungshin Kim, Jang Mok Kim, "Extraction of Induction Motor Fault Characteristics in Frequency Domain and Fuzzy Entropy", 2005 IEEE Int. Conf. on Electric Machines and Drives, San-Antonio, TX, pp. 35-40.

[9] Irahis Rodriguez, Roberto Alves, "Detection of the Combination of Static and Dynamic Air gap Eccentricity in 3-Phase Induction Motors using Stator Current Monitoring", ICEM'06, Chania, Crete Island, Greece, Sept. 2-5, 2006.

[10] J. Faiz, B. M. Ebrahimi, "Mixed fault diagnosis in threephase squirrel-cage IM using analysis of air-gap magnetic field", Progress In Electromagnetics Research, PIER 64, pp. 239-255, 2006.

[11] Jordi Cusido, Javier Rosero, Emiliano Aldabas, Juan Antonio Ortega and Luis Romeral "New fault detection techniques for induction motors", Electrical Power Quality and Utilization, Magazine vol. II, no. 1, pp. 3946, 2006.

[12] M'hamed Drif, A. J. Marques Cardoso, "Instantaneous non-active power approach for air gap eccentricity fault diagnosis in three-phase induction motors", Journal of Acta Electrotechnica and Informatica, vol. 8, no. 3, pp 18-25, 2008.

[13] Ilker Ozelgin, "Analysis of magnetic flux density for airgap eccentricity and bearing faults", International Journal of Systems Applications, Engineering \& Development, vol. 2, issue 4, 2008.

[14] Yountae Kim, et al, "Fault Diagnosis of AC Servo Motor with Current Signals Based on Wavelet Decomposition and Template Matching Methods", Proceedings of the 17th World Congress of The International Federation of Automatic Control, Seoul, Korea, July 6-11, 2008.

[15] Martin Blodt, et al, "Models for Bearing Damage Detection in Induction Motors Using Stator Current Monitoring”, IEEE-TIE, vol. 55, no. 4, pp. 1813-1822, 2008.

[16] P.V.J. Rodríguez, A. Belahcen, A. Arkkio, Antti Laiho, J. A. Antonino-Daviu," Air-gap force distribution and vibration pattern of Induction motors under dynamic eccentricity", Electr. Eng., vol. 90, no. 3, pp. 209-218, 2008.

[17] J. Faiz, and B. M. Ebrahimi, "Static eccentricity fault diagnosis in an accelerating no-load three-phase saturated squirrel-cage induction motor", Progress In Electromagnetics Research B, vol. 10, pp. 35-54, 2008. 
[18] J. Faiz B.M. Ebrahimi, B. Akin and H.A. Toliyat "Dynamic analysis of mixed eccentricity signatures at various operating points and scrutiny of related indices for induction motors", IET Electr. Power Appl., vol. 4, issue 1, pp. 1-16, 2010.

[19] G. G. Rogozin, D. Y. Osipov, "Induction Motor Eccentricity Diagnosis Using Impedance Spectrum and Shaft Voltage", XIX International Conference on Electrical Machines - ICEM 2010, Rome, 6-8 Sept. 2010.

[20] A. Metatla, S. Benzahioul, T. Bahi, and D. Lefebvre, "Monitoring and diagnostic methods for eccentricity faults in the induction motor", Proceedings of the International Conference on Circuits, Systems, Signals, Malta, pp. 85-91, 2010.

[21] J.R. Briso-Montiano, R. Karrelmeyer, and E. Dilger, R. Bosch, G. Stuttgart, "Simulation of Faults by means of finite element analysis in a switched reluctance Motor", Expert from the proceeding of the COMSOL Multiphysics User's Conference, Frankfurt, 2005.

[22] H. Torkamanand, and E. Afjei, "Magnetostatic field regarding analysis regarding the effect of eccentricity in switched reluctance motor", Progress In Electromagnetics Research M, vol. 8, pp. 163-180, 2009.

[23] H. Torkaman and E. Afjei, "Hybrid method of obtaining degrees of freedom for radial airgap length in SRM under normal and faulty conditions based on magnetostatic model", Progress In Electromag. Research, PIER 100, pp. 37-54, 2010 .

[24] L. Chen, W. Hofmann, "Analysis of Radial Forces Based on Rotor Eccentricity of Bearingless Switched Reluctance Motors", XIX International Conference on Electrical Machines - ICEM, Rome, 2010.

[25] R. Krishnan, SRM Drives: Modeling, Simulation, Analysis, Design and Applications, Ind. Electronics Series.

[26] Xiang-Dang Xue, K. W. E. Cheng, and S. L. Ho, "Simulation of SRM Drives Using Two-Dimensional Bicubic Spline”, IEEE Trans. on E.C., vol. 17, no. 4, pp. 471-477, Dec. 2002. 